\title{
The Evolution of Health Care Delivery in American Industry
}

\author{
by Warren L. Moser*
}

The Evolution of Health Care Delivery is an issue that in the last few years has become a matter of vital concern for all American businesses and industries. I refer, obviously, to the insidious and seemingly uncontrollable rise in the cost of medical care and what American industry is doing to stem that tide.

The possible causes for this escalation in cost are numerous - and a strong thesis could be drafted in support of each of them. I've been asked to confine my remarks to three main points :

- A description of how my firm, Southwestern Bell Corporation, provided health protection for our employees prior to the advent of Health Maintenance Organizations - or HMOs, as we usually refer to them.

- Southwestern Bell's experience with HMOs and why we have not found them to be the best solution.

- And, finally what our new approach to medical delivery is and why we believe it will be a desirable direction for the future.

In a word, I will cover the evolution of health care delivery in American industry in general, and in my company in particular.

First, let me give you a little background information about our corporation.

Southwestern Bell Corporation is one of the seven regional holding companies created as the result of the government imposed divestiture of the American Telephone and Telegraph Company in 1984.

Our corporation is comprised of a number of subsidiaries including Southwestern Bell Telephone Company which provides local telephone service to customers in the states of Arkansas, Kansas, Missouri, Oklahoma, and Texas.

We employ more than 68,000 people in our subsidiaries and holding company and have more than 25,000 retirees. The majority of our employees are members of labor unions with benefits provided as a negotiated part of their contracts with us.

\footnotetext{
${ }^{*}$ Director of Corporate Benefits, Southwestern Bell Corporation St-Louis, Missouri, USA
} 
Southwestern Bell Corporation is ranked 22nd in net profits among the top 500 American corporations as defined by Forbes Magazine. We are ranked as the sixth largest of the top 50 utilities as identified by Fortune Magazine.

As you can imagine, for a company our size, health care is a major expense item and is a matter of great concern for our corporation, our active employees, and our retirees.

With these facts in mind, let me begin to trace for you the evolution of Southwestern Bell's health care programs.

The union in our company, as we know it today, really began in the late 1940's and early bargaining in that post World War II era concentrated on two main points - wages and working conditions.

While we had instituted a pension plan in 1913, no other benefit plan of any type was introduced until 1957, when a group life insurance plan was negotiated with the union.

Our first health care benefit was negotiated with the union and introduced in July 1960. This was a company paid Major Medical supplement to a basic plan which the company made available to employees at the employees' expense.

The first negotiated Basic Medical Expense Plan with our union became effective in March of 1964.

An interesting point about the early negotiations of our basic medical plan is that we really did not bargain over the level of coverage in the plan itself.

We purchased from the only major provider of group health plans at that time - Blue Cross/Blue Shield - their plan and their level of benefits. This contract provided reimbursement for medical expenses according to a fixed schedule.

What was really negotiated with the union was that the company agreed in 1964 to pay $25 \%$ of the premiums for the Blue Cross/Blue Shield plan. In 1967, through negotiations, our contribution was increased to $50 \%$, to $75 \%$ in 1968 , and finally in 1971 to $100 \%$.

Medical cost escalation was not a problem during most of this period. Looking back, it is not suprising that this was true. The plans provided for reimbursement according to a fixed schedule and the employees, for much of this period, bore the brunt of the premium cost.

These were two effective suppressants to cost escalation.

It is significant, I think, to realize that we, like nearly all companies at that time in America, were only negotiating a means for our employees to obtain medical care.

There was little thought given to containing costs.

In retrospect, it is not surprising what took place over the last 25 years.

By analogy, it was as though in 1963 we bargained with the unions to provide every employee with a new automobile. In the early 1960's when employees paid most of the costs, they selected a low priced auto. By the late 1960's, when we paid half the cost, they wanted a moderately priced car. And, by 1971 , when we paid all the cost, they quite naturally wanted a Mercedes or Rolls Royce.

In 1965, the Federal Government introduced legislation providing medical care for the elderly through government insurance called Medicare. 
Interestingly, the medical community fought the introduction. Doctors and hospitals alike thought it would lead to their financial decimation.

It subsequently proved to be one of the greatest causes of cost increase our economy has ever known.

In the early 1970's another concept was introduced into the medical delivery system a concept called reasonable and customary $-R \& C$. It has also been referred to as UCR usual, customary and reasonable and several other acronyms as well.

Basically, it was a response to pressure from the Unions about the growing inadequacy of benefit schedules in the medical plans over the life of multiple year contracts (which were, by the 60 's and 70 's, becoming standard settlements throughout all large American industries).

What $R \& C$ was intended to do was to eliminate the need for periodic schedule adjustments. Insurance companies would maintain profiles of charges for all physicians and surgeons by procedure, by speciality and by locality. They would determine from the profile of charges submitted by the doctors what the reasonable and customary charge for each service should be and reimburse the physicians according to that profile.

What transpired after that is history.

The medical community very quickly learned how the system worked and indentified that, by submitting higher charges, they automatically increased their profile in a very short time.

The introduction of Medicare and $\mathrm{R} \& \mathrm{C}$ were not the only forces increasing costs in that period, but indeed they were major factors.

By the mid to late 1970's, some of us in the benefit field were starting to identify what was taking place. But business was strong, profits were high, and there was little inclination on the part of upper management to heed any warning signs called to their attention.

At that time, Southwestern Bell was a part of the American Telephone \& Telegraph Company and our benefit programs were bargained nationally by AT \& T .

In 1976, Southwestern Bell submitted to AT \& T a suggested revision to the Bell System's medical plan. The redesign consisted of the introduction of a comprehensive-type plan with front-end deductibles and a $20 \%$ co-payment by the employee for all covered services.

But in the late 1970's, neither AT \& T nor any other major company in the United States was willing to risk a strike for a more cost effective medical plan.

So, medical plan designs ill-conceived to control costs, the introduction of Medicare making medical care affordable to millions of people previously excluded from the system, and bargaining pressures for altering features in the plans which were discomforting to union members, in combination were producing percentage cost increases in the 1960's and 1970 's of anywhere from 12 to $25 \%$ per year.

Admittedly, some of that increase was the result of plan improvements but the bulk of it was nothing more than cost and utilization escalation within the medical delivery system. 
By the early 1970's, there was an emerging recognition by both government and business that something had to be done to help turn the tide of rising health care costs.

One concept that eventually found its way into the system was not new. The Health Maintenance Organization dates back to pre World War II days although only a few existed prior to the introduction of a federal HMO law in 1973.

This law provided federal financial assistance to HMOs that met certain specified standards and criteria: It required employers to offer HMOs to their employees on the same basis and with the same financial assistance provided under their traditional health plans.

In general, American industry was in strong support of HMOs because they were perceived as perhaps the only available solution to the drastic and continuing cost escalation problem.

We at Southwestern Bell had a very positive attitude toward HMOs. In fact, we went beyond the requirements of the law by developing and paying for intensive internal informational programs encouraging employee enrollment. And, we continued this encouragement throughout the 1970's and early 1980's.

However, our hopes that HMOs would provide the long-term cure for our country's health care cost disease are proving to be false hopes.

A number of HMOs have gone bankrupt because they were not properly managed or were financially unsound. And, these bankruptcies have had a dramatic and unsettling effect on our employees.

In addition, HMOs have failed to attract significant numbers of employees. In our five states where some $47 \mathrm{HMOs}$ have mandated us under the law, only 10 to $12 \%$ of eligible employees have enrolled.

Except for the West Coast and a few isolated locations in other parts of the country, this is not out of line with the percentages experienced by many other major employers.

But perhaps the most alarming problems with HMOs are those only now emerging. Until the mid 1980's there was no data available on who the HMO participants were or their level of medical services utilization.

Recent studies conducted by Southwestern Bell and several other major companies have now shown that, contrary to predictions, the people actually joining HMOs are generally young, single or married employees without children, and significantly lower than average users of medical services.

As a result, because we were reimbursing the HMOs any equivalent cost for employees under our standard plan, we were actually losing money two ways.

The average utilization of people remaining in our traditional plan was higher (because of the number of low users who transferred to HMOs) and our resulting reimbursement rate went up.

So, we were paying HMOs a higher rate than appropriate for the risks we were transferring to them. Our studies showed this cost at something slightly in excess of $\$ 100$ per year per employee when we ran a study back in early 1985 . 
And, the high utilizers who remained in our basic plan typically were older individuals, frequently suffering from some chronic condition and thus usually with an established relationship with a doctor, which they didn't want to change.

So HMOs, while conceptually sound, did not prove to be the solution desperately needed by American industry in the mid 1980's.

Another concept, the Preferred Provider Organization, or PPO, should be mentioned.

PPOs have only recently been introduced. By recently I mean in the 1980's. PPOs are groups of health service providers, doctors or hospitals, who agree to provide medical services at discounted rates through direct contracts with the purchaser - usually a major company or union. The discounts are given in response to anticipated increases in business from the purchaser.

Close analysis of PPOs also revealed major flaws. Many PPO's provided discounted prices, but offered little or no control over utilization. They also required significant internal resources to establish contracts, monitor results, and insure against increased utilization.

In addition, plans like ours with high front-end coverage required substantial redesign in order to deliver the significant numbers of employees to the PPOs necessary to obtain the discounted fees.

This, then, was the status of health care delivery nationally and in Southwestern Bell when our company formed a Benefit Planning Group for the first time in August of 1985.

Prior to the break up of AT \& T, all benefit planning work was performed by AT \& T on behalf of the entire Bell System.

We immediately established six corporate objectives for use in addressing the health care cost issue :

- Reduce present costs

- Contain future costs

- Maintain the current level of post-retirement benefits

- Promote wellness

- Protect employees from catastrophic risks

- Meet certain Human Resource requirements

With these objectives in mind, we sought a new plan. It was obvious that our current plan could not address the rising costs. HMOs had not presented a solution. And, PPOs had too many inherent problems as outlined previously.

Whatever we came up with would have to have four qualities to be acceptable :

- It would have to be easy to understand.

- The system would have to be easy to use.

- The claims procedure must be simple.

- Quality of care would have to remain high. 
But, candidly, of all of these goals, objectives and required qualities, the highest priority was containment of costs.

When we looked at the statistics, it was no wonder that this was the highest priority. Medical expense per employee from 1980 through 1985 was two to three times the Consumer Price Index for Wages of the Medical CPI.

And, from 1979 to 1985 medical expense per employee increased $217 \%$.

It was even more compelling when we projected the costs through 1989. Projecting the 1984 through 1985 expense per employee trend through 1989 indicated it would cost Southwestern Bell Corporation an additional $\$ 130$ million over that period.

And, Southwestern Bell did not face this rapidly escalating health care cost spiral alone. For the entire United States economy, health care expenditures grew more than $800 \%$ from 1960 to a $\$ 425$ billion total in 1985 .

Even more dramatic is the fact that in 1960 health care expenditures accounted for $5.3 \%$ of the gross national product (GNP); by 1985 health care expenditures had risen to $10.7 \%$ of the GNP. This more than doubling as a percentage of GNP has made the health care industry one of the largest industries in the United States.

Of course our union - the Communications Workers of America - also had objectives they wanted to see included in any future health care plan.

They wanted to avoid cost shifting of benefit expense to the employees. This meant resistance to increased co-payments and deductibles. And, they would accept no reduction in benefit levels.

However, the union appeared amenable to certain cost containment activities. Those included :

- More efficient claims processing

- Use of second opinions on surgery

- Wellness programs

- Alternative health care systems such as HMOs and PPOs.

They also seemed willing to discuss pre-certification and utilization review programs.

After examining the requirements from the various points of view, we determined there was no product available on the market to meet all our objectives. Our decision was to design our own plan custom designed by us, for us.

We started by an in-depth analysis of the four basic components of health care :

- Price

- Utilization

- Quality

- Availability

Realizing that quality and availability could not be reduced, we focused on price and utilization.

Even cursory analysis of the medical delivery system quickly showed that as prices are reduced, utilization increases and health care costs will continue to rise. 
Also, controlling utilization by itself will result in proportionate increases in price so that health care costs will continue to increase.

Our goal clearly had to be to effectively control both price and utilization without jeopardizing quality and availability in effect, to develop a truly managed medical care delivery system.

The system we came up with we have called Southwestern Bell CustomCare.

CustomCare takes the most attractive parts of HMOs, PPOs, and indemnity delivery systems and effectively blends them together.

From HMOs we have taken :

- Pre-certification

- Utilization Review

- Wellness Emphasis

From PPOs :

- Negotiated provider discounts

And, from indemnity plans :

- Flexibility

- Freedom of choice

CustomCare will provide the best of all worlds for Southwestern Bell's employees.

Let me briefly describe what CustomCare is and how it will work.

We have engaged The Prudential Insurance Company to establish a network of physicians and hospitals in some 18 major metropolitan areas where approximately $80 \%$ of our employees and retirees live.

These networks will deliver all medical services required by our employees at a level at least equivalent to our current plan (and in many cases greater) with only a $\$ 5$ co-payment for a visit to the doctor's office.

So long as the employee receives services from a participating network physician and at a participating network hospital, that is all they pay.

By remaining in the network, they need file no medical claims and the pre-certification, second surgical opinion and utilization review process required for out-of-network services is all done within the physician groups and is transparent to the user.

In addition, they have added benefits such as home health care, hospice care, wellness programs and well child care, all of which are not available to them in the out-of-network portion of the plan.

However, CustomCare recognizes that our employees do not like to be locked into a program for a full year (as is true under the HMO programs).

As a result, our plan provides the employee (or dependent) full freedom, on a service by service election, to opt into or out of the network at any time.

However, in doing so, since their services now will cost the company more to provide, the employee will incur a front-end deductible and a $20 \%$ co-payment.

Initially, the annual deductible is set at $\$ 200$ progressing to $\$ 250$ in the second year of the contract and finally to $\$ 300$ in 1989 . 
In addition, for out-of-network services the employee will be obliged to file a claim form to obtain reimbursement and all services will be subject to a full range of cost containment programs such as pre-certification, second surgical opinion, utilization review, and hospital discharge planning.

As I mentioned, about $80 \%$ of our employees live in metropolitan areas in which we anticipate establishing CustomCare networks.

The remaining $20 \%$ will continue their coverage under our current first dollar indemnity health plan but with a number of cost containment features such as pre-certification, second opinion surgery, and utilization review.

What's special about CustomCare is that it in effect makes each employee a member of both an HMO and of a constrained indemnity plan.

This gives the employee the option of sometimes using the HMO plan with its advantages and at other times using the indemnity plan with its advantages.

CustomCare will give employees far greater incentives to become intelligent, informed consumers of health care. Every contact under this plan will require an employee to compare advantages of the options offered.

In this plan, employees have a much wider choice than if they were members of a conventinal HMO. And, the cost of that wider choice is limited also, because many routine services can be received from the HMO network at little or no cost.

Each CustomCare network will consist of qualified health care professionals and facilities that are available to serve the health car needs of all eligible employees, retirees and their dependents.

The network will consist of an adequate number of primary care physicians, specialty physicians and health care facilities which are geographically dispersed so that the network is convenient, easy to use and responsive to health care needs.

The CustomCare reimbursement of network health care providers very subtly creates a balanced control over these networks.

Our payment arrangement with the carrier diminishes the normal tendency of completely capitated plans toward under utilization. This is because each physician is reimbursed on a discounted fee-for-service basis by the carrier with a substantial percentage withhold from those fees.

To retard possible over utilization, the withhold on each reimbursement goes into a risk sharing pool. If the utilization of the entire eligible group meets, or is lower than, the set utilization targets for both hospital and physician care, the physicians split the withhold on a proportionate basis. If utilization exceeds the target, the excess utilization is paid for from the withhold pool before any distribution takes place.

But, perhaps the greatest assurance of quality comes from the provision giving the employee the freedom to opt out of the network at any time. No physician can afford to diminish quality or delay accessibility if he risks losing a patient because of it. 
In addition, quality of care will be constantly monitored by physician peer review panels, by the insurance carrier, and by Southwestern Bell. Quality review will minimize both under-treatment and over-utilization to yield a balanced, effective medical care system.

$\mathrm{SBC}$ is now in the throes of CustomCare implementation. In my December presentation to this association, I stated our first two networks would be on April 1, 1987.

However, our implementation is behind schedule due to several factors. I will touch on only two of the ones I feel you will find or interest.

First, as we started the implementation process, we had a difficult time determining what constituted an adequate network in each of our 18 metropolitan areas. After several months of analyzing networks from different persepctives, we were still uncertain if a specific network met the health care needs of our employees and retirees in a given metropolitan area.

Finally, we sat down with our carrier, Prudential, and agreed to a network approval process. This process included testing each network from three aspect :

- Numerical sufficiency

- Geographical distribution

- And employee/retiree perceptions

To fulfill the numerical sufficiency test, the networks would have to include a sufficient number of primary care physicians, specialists, chiropractors, pediatrists, hospitals, and other health care facilities to adequately serve the employees and retirees in a given network area. Specific benchmarks expressed on a per-eligible basis were established.

The geographical distribution test would be performed after the numerical sufficiency test had been passed. The first step would be to divide a given metropolitan area into population centers. These centers are determined by the medical marketplace, where our employees and retirees reside within that metropolitan area, natural boundaries, and local practice.

Once the population centers were established, the percent of SBC employees and retirees living in each center would be compared to the percent of health care providers, by category, located in each center. Again, specific benchmarks were established based on the number of employees and retirees residing in each population center.

The employee/retiree perception test looks at the percent of network providers our employees and retirees have previously used. In other words, we want to know how many employees and retirees will have to change providers to receive networks services.

A committee of corporate and local benefit personnel review test results and determine if each network is adequate and ready for implementation.

This network approval system has dramatically streamlined our decision making process while at the same time expanded the number of significant network adequacy criteria analysed.

The second factor that delayed our implementation schedule is rather difficult to quantify. The best description of this factor may be "the newness of it all". 
To a degree, our bold step into this new world has created problems for all our people from our highest level executive, to our oldest retiree, to our youngest employee. This "newness" has also affected our medical plan carrier and - maybe most significantly - the medical providers.

I won't take time to address the new problems that CustomCare has created for the carrier and provider community. But I do want to discuss the problems CustomCare has crated for our employees and retirees.

Change seems to breed confusion and uncertainty. When either of these exist, and especially when they exist simultaneously, there is a potential for concern. In spite of a massive communications effort including numerous articles in company publications, numerous special bulletins to each employee, training sessions for all employees and retirees, and special presentations and information packets for executive personnel, confusion and uncertainty seemed to abound.

When a company decides to embark upon a similar medical delivery path it must identify the confusion and uncertainty aspect of this change and map out a clear strategy for addressing this issue.

There is one other update I feel you will find of interest.

We believe there is great potential for CustomCare to have a positive impact on our health care expense. This belief, reached through careful study, has guided us through the planning and implementation phase of our program.

However, we feel strongly that there must be a means to measure CustomCare's actual cost effectiveness. We did not want to repeat the mistake made by the early planners of HMOs. Ten years after the HMO concept was introduced, program administrators decided to conduct studies of available data only to find that the programs were actually costing money instead of providing a savings.

So, we have contracted with Johnson \& Johnson Health Management, Inc. to develop a process for an objective evaluation of the CustomCare program.

Through this process, we will assure that the desired savings are achieved and assess whether CustomCare has reduced SBC's health care cost increases. We also want to determine the changes in employee satisfaction with our medical benefits and measure, to the extent possible, the quality of care delivered by custom Care network providers.

Collection and analysis of data will begin simultaneously with the implementation of the first network July 1 . Preliminary results are expected next spring. A final report will be provided in the winter of 1990.

Having this information as the CustomCare program is evolving will allow us to make any mid-stream adjustments and will provide us with a true picture of the program for use during future bargaining sessions with our union. 
In conclusion, I wish I could stand before the Reader and provide data proclaiming our success with this system. Our expectations are high both for our ability to control costs, as well as quality. Our conversations with all the carriers who bid on the program, as well as The Prudential, the one that will deliver it, have revealed a strong opinion that we are on the right track.

Needless to say, we are excited. In many respect, I feel like an expectant mother elephant - I've been pregnant for a very long time and I can hardly wait to see our new baby. 